\title{
Bacteriuria Asintomática en el Embarazo
}

\author{
UNIVERSIDAD NACIONAL DE COLOMBIA \\ FACULTAD DE MEDICINA \\ DEPARTAMENTO DE GINECOLOGIA Y OBSTETRICIA
}

\author{
Dres.: Antonio Lomanto Morán*, Jacinto Sánchez Angarita**, \\ Alfredo Lomanto Castañeda***
}

\section{INTRODUCCION}

Las infecciones de vías urinarias, que incluyen la Bacteriuria Asintomática (BA), la Cistitis y la Pielonefrit is Aguda, son comunes en las embarazadas y no embarazadas. Aunque la gestación en sí no incrementa la prevalencia global de estas infecciones en mujeres, hay cambios que aumentan la incidencia de la infección sintomática aguda y en particular la pielonefritis aguda. Esta última es rara en la no embarazada, en tanto que durante el embarazo se transforma en el trastorno méaiico más común.

Las infecciones agudas de vías urinarias constituyen una fuente de complicaciones graves para la embarazada y el feto. En su forma más grave, la pielonefritis agu da y la endotox emia resultante pueden ocasionar insuficiencia de múltiples órganos y sistemas de la gestante, con deterioro concomitante de la unidad útero-placentaria-fetal (1.2).

Muchas de las mujeres que sufren infecciones agudas de vías urinarias durante el embarazo, pertenecen a un pequeño grupo que pueden identificarse desde la primera visita prenatal, como portadoras de BA, y ésta a su vez puede definirse como la presencia de bacterias en multiplicación activa en algún punto de las vías urinarias, excepto en la zona distal de la uretra, en un momento en que la mujer no tiene síntomas. De 20 a $30 \%$ de las embarazadas con BA detectadas al comienzo de la gestación, si

Director Departamento de Ginecología y Obstetricia.

Instructor Asociado, Departamento de Ginecología y

Obstetricia

Residente III. Departamento de Ginecología y Obstetricia. no reciben tratamiento, sufrirán pielonefritis aguda más tarde, por lo regular en el tercer trimestre (3, $4)$. Se ha demostrado ampliamente que el tratamiento con alguno de los antimicrobianos disminuirá al 3\% aproximadamente. De acuerdo con el anterior concepto, la bacteriuria asintomática es de suma importancia en la etiología de la Pielonefritis Aguda durante el embarazo y por lo tanto en todas las mujeres se practicarán pruebas de detección de las mismas, en la primera visita prenatal, seguida de la terapéutica antimicrobiana adecuada y vigilancia con base en cultivos de orina.

\section{Prevalencia}

La prevalencia de la Bacteriuria Asintomática durante el embarazo, es del 2 al $7 \%$ según el estado socioeconómico de las mujeres estudiadas (5).

Estudios a gran escala de mujeres entre los 20 y 50 años de edad han demostrado que la frecuencia de bacteriuria era constante y fluctuaba entre el 3 y el $7 \%$, aumentando al $10-25 \%$ en las mujeres mayores de sesenta años. Puesto que la mayor parte de las infecciones sintomáticas en la mujer surgen de una infección asintomática preexistente, esta bacteriuria asintomática señala el sector de la población femenina en el cual surgirán enfermedades sintomáticas agudas si no es tratada.

La mayor frecuencia se observa en las mujeres de bajo nivel socioeconómico. Otro factor del huésped que influye en la incidencia de la BA es la presencia del rasgo depranocítico y muestra frecuencia doble en gestantes con el rasgo mencionado en relación con aquellas de similar estado socioeconómico que carecen de la hemoglobina drapanocítica (6). 
Las mujeres con BA tuvieron más frecuentemente anemia, que los controles al ser visto por primera vez y mostraron también evidencia de incremento de la anemia con el progreso del embarazo. El tratamiento de las pacientes que tuvieron BA en el embarazo tempranamente, con el antibiótico previno el desarrollo de la anemia (4).

\section{Etiología}

Las Enterobacteriáceas son causa del $80 \%$ de las infecciones bacterianas de las vías urinarias. No hay un síndrome único que se asocie con alguna especie en particular. La E. Coli es el agente causal del $80 \%$ de las infecciones urinarias adquiridas, con varios tipos séricos causantes de un gran número de infecciones, sobre todo cuando se compara con su frecuencia en la flora fecal. La Klepsiella Spp provoca alrededor del 5\% de infecciones, Enterobacter Spp y Proteus Spp sólo dan lugar al 2\% de las infecciones extrahospitalarias. Las infecciones por Proteus a menudo coinciden con infecciones renales y requieren de exploración más profunda y tratamiento activo. Serratia Marcescens y Pseudomonas aureginosas son casi siempre infecciones adquiridas en el hospital y debidas a fallas en las medidas del control, por lo general después del cateterismo uretral.

Los Anaerobios obligados rara vez causan infección de vías urinarias, a pesar de su predominio en las heces (mil millones por gramo de heces). Se supone que la presencia de 02 en la orina impide su crecimiento y persistencia en las vías urinarias.

Stafilococus Saprofiticus es el segundo patógeno más frecuente en mujeres jóvenes, aislado en la mayor parte de los exámenes y causa aproximadamente el $10 \%$ de las cistouretritis aguda (7).

El reservorio de estos microorganismos aún se desconoce. Stafilococus epididimus es causa frecuente de infecciones uterinas intrahospitalarias en pacientes cateterizadas y suele ser resistente a muchos de los agentes antimicrobianos. Otros microorganismos gram positivos, incluso estreptococus $\mathrm{P}$ y D son causa casi del 1 al $2 \%$ de las infecciones de vías urinarias.

\section{Diagnóstico}

El diagnóstico de BA se basa en los cultivos cuantitativos de orina para identificar la Bacteriuria. Con toda seguridad son importantes "dos muestras de orina limpia", de modo que cada una genere la misma especie de microorganismo y un recuento de colonias superior a 100.000 gérmenes por $\mathrm{ml}$ de ori- na. El problema en este caso es diferenciar entre las bacterias que están en la orina como consecuencia de contaminación durante la toma y la que se multiplica activamente dentro de las vías urinarias. Casi todas las muestras que se contaminan durante la recolección contienen menos de mil microorganismos por $\mathrm{ml}$, en tanto que el caso de infección bacteriana suelen exceder de 100.000 microorganismos por ml de orina.

Como dato importante la exactitud de un cultivo de orina depende en gran parte de los métodos utilizados para la recolección y procesamiento de la muestra. Para evitar la contaminación bacteriana excesiva hay que instruir a la mujer para que se haga antisepsia de la vulva en dos ocasiones y tomar la muestra de la parte media de la micción. De ser posible la orina debía haber permanecido en la vejiga, por lo menos durante 4 horas y no debe ser producto de diuresis forzada. Por último, la orina debe ser cultivada inmediatamente o llevada a un refrigerador para cultivo posterior y así evitar la multiplicación de contaminantes bacterianos (8).

Casi en todas las pacientes con infección bacteriana de vías urinarias se encuentra piuria. Aunque la determinación de la cifra de excreción de leucocitos es complicada y poco práctica, el recuento de leucocitos en el hemacitómetro es en realidad sencillo. En el $95 \%$ de las pacientes con bacteriuria está aumentada (más de 10 leucocitos por ml).

En mujeres normales sin bacteriuria, menos del $1 \%$ de las muestras tienen más de 10 leucocitos por ml. En cambio más del $90 \%$ de las pacientes con síndrome uretral agudo de origen bacteriano incluyendo Chlamidia Trachomatis o con cistouretritis, BA, y bacteriuria adquirida posterior a cateterismo, tienen más de 10 leucocitos por ml. Así, estos estudios indican que la colonización de la mucosa de las vías urinarias sin reacción inflamatoria del huésped es poco frecuente. Sin embargo, para determinar si el análisis cuantitativo de la excreción de leucocitos podría ser un procedimiento más útil, con el objeto de detectar a las pacientes con infección a pesar de recuentos bacterianos bajos, es necesario realizar otros estudios.

Todas las mujeres con posible infección renal deben someterse a una pielografía intravenosa con el fin de identificar cualquier alteración estructural. Por lo general, tales alteraciones no se desarrollan en la vida adulta como consecuencia de infección y por lo tanto, rara vez se indica la repetición del estudio. En la mujer no suele ser necesario realizar una cistourografía de vaciamiento aunque después 
de la pielografía I.V. se recomienda obtener una post-miccional. Si la función renal es normal, los estudios retrógrados con material de contraste casi nunca son necesarios, ya que la pielografía intravenosa proporciona más información acerca del tamaño, función del riñón, sin el riesgo de introducir infección y sin el traumatismo causado por el cateterismo uretral y ureteral. El estudio no está indicado en mujeres con síntomas exclusivamente vesicales si mejoran con tratamiento de dosis única.

La exploración citoscópica con evaluación descriptiva de la mucosa uretral y vesical es de poca utilidad para el tratamiento de la infección de las vías urinarias de la mujer. Sólo cuando la presencia de eritrocitos $\mathrm{u}$ otros signos sugieren neoplasia, o los estudios radiológicos indican reflujo para evaluar a la mujer con cistouretritis, serán necesarias unas Cistoscopias (9).

\section{Complicaciones de la Bacteriuria Asintomática}

Si la BA conduce a un parto prematuro todavía permanece siendo un tema muy controvertido (10). Kass, publicó un estudio en donde afirma que hay un riesgo elevado de prematuridad y de pérdida fetal en la mujer embarazada con bacteriuria persistente y estableció que el riesgo podría reducirse significativamente mediante la administración de agentes antimicrobianos durante la gestación (7). Una revisión completa de Whalley (11) reveló que cuando cada paciente bacteriúrica era comparada con una paciente sin bacteriuria, las tasas de prematuridad de los dos grupos eran similares (11). Sin embargo, se observó un incremento de partos pretérminos, en aquellas mujeres bacteriúricas que desarrollan una pielonefritis antes del comienzo del parto. Por ello la prevención de la pielonefritis podría ser uno de los factores fundamentales en el descenso de la tasa de prematuridad. Utilizando el examen de anticuerpos fluorescentes como método de localización y el isótopo del yodo, se demostró que no existía una diferencia estadísticamente significativa en las tasas de prematuridad del grupo no bacteriúrico y del grupo total de pacientes bacteriúricas. Sin embargo, un porcentaje mayor de madres bacteriúricas con un examen de anticuerpos fluorescentes positivos dieron a luz niños con un retraso del crecimiento intrauterino. Para los niños con dicho retardo la evidencia de enfermedad renal crónica materna incluía los valores de aclaramiento de creatinina bajos, las elevaciones de la presión diastólica y la existencia de anticuerpos fluorescentes positivos.
Por ello mediante este examen de localización, era posible identificar un grupo de pacientes bacteriúricas que padecían una enfermedad renal que estaban, por ello, en riesgo de presentar una alta incidencia de niños con un retardo del crecimiento intrauterino $(7)$.

En el estudio de Kass, puede ser que hubiese una alta incidencia de enfermedades renales no diagnósticas. Una publicación posterior de este centro establece que la tendencia a la prematuridad puede estar limitada a aquellas pacientes cuya bacteriuria sigue un curso complicado.

Brumfitt (4), estableció que los efectos adversos de la BA sobre la salud fetal no son dramáticos y por ello una tendencia de los médicos a ignorarla, o al menos no se la toma en serio. A pesar de los hallazgos menos dramáticos, existen evidencias que la BA no tratada durante el embarazo incluso cuando es asintomática tiende a producir un resultado fetal menos favorable. El mismo autor observó que cuando los pesos medios al nacer se colocaban en forma ascendente los más bajos se asociaban con bacteriuria no tratada. Este se relaciona con los hallazgos de Harris en los que se observó que los niños con peso más bajo al nacer eran de madres con bacteriuria (7). No hay incremento de la incidencia de anomalías congénitas de niños nacidos de madres con infección del tracto urinario. Las anomalías congénitas mínimas han ocurrido como el resultado del tratamiento, como por ejemplo administración de tetraciclinas. Cuando se administra tetraciclina en el último trimestre de gestación atraviesa la placenta y produce una decoloración amarilla de los dientes del recién nacido.

Las complicaciones de la Bacteriuria Asintomática durante el embarazo pueden ser consideradas con relación a la madre y el feto. Una variedad de efectos adversos sobre la madre han sido descritos incluyendo el desarrollo de pielonefritis aguda, anemia, toxemia, bacteriuria persistente y pielonefritis crónica. La asociación más interesante está en la presencia de bacteriuria en el primer trimestre y el desarrollo de pielonefritis aguda, la cual ocurre durante el tercer trimestre (10).

\section{Tratamiento}

El tratamiento antimicrobiano seleccionado para el manejo de las infecciones del tracto urina. rio durante el embarazo es extremadamente impor. tante no sólo para la resolución de la infección sine 
también para el bienestar continuado de la madre y el feto. Es diferente del que habitualmente se utiliza para pacientes no embarazadas con infecciones del tracto urinario.

Como ciertos agentes antimicrobianos pueden ser nocivos para el feto, la utilización de una droga segura es una de las consideraciones más importantes. Casi todas las sustancias farmacológicas atraviesan la barrera placentaria y la respuesta del feto a la droga suele ser diferente de la que presenta la madre. Habitualmente una respuesta típica es un aumento de la toxicidad debida a un incremento en la permeabilidad del cerebro y la función inmadura de las enzimas hepáticas fetales.

El microorganismo que con mayor frecuencia se identifica en la bacteriuria asintomática es el E. Coli, razón por la cual la selección inicial de cualquier antimicrobiano suele ser empírico y se ha demostrado que son innocuos y eficaces agentes como sulfonamidas, nitrofurantoinas, ampicilina y cefalosporinas. Todos son excretados por el riñón y alcanzan concentraciones en la orina mucho mayores de las necesarias para combatir todas las infecciones de vías urinarias por E. Coli. Un tratamiento de 10 a 14 días con cualquiera de los cuatro antimicrobianos mencionados, erradicarán la BA en $65 \%$ de las embarazadas aproximadamente (13).

Se han acumulado pruebas de que cuando menos en la mujer no embarazada una sola dosis de antimicrobiano es muy eficaz para combatir las infecciones sintomáticas de vías urinarias que se limitan al tracto inferior como sería la cistitis.

No se ha evaluado extensamente la importancia de una sola dosis de antimicrobiano en el tratamiento de la bacteriuria asintomática durante el embarazo, pero los pocos estudios publicados señalan un índice de cura inicial semejante con el tratamiento corriente de dos semanas. Harris y colaboradores (7), con una sola dosis de dos gramos de ampicilina sumada a un gramo de probenecid, curaron el $71 \%$ de embarazadas con bacteriuria asintomática. Los resultados son prometedores, pero el número total de casos que se han estudiado es muy pequeño y se necesitan más investigaciones para que se pueda prẹcisar la importancia absoluta de estos tratamientos en particular por estudio y todos han demostrado que la bacteriuria asintomática afecta el riñón en el $50 \%$ de los casos, en promedio.

Los principales beneficios de una sola dosis serían, menos costo, menos efectos adversos, peligro potencial menor para el feto y seguridad del cumplimiento de las órdenes médicas por parte de la paciente. Otro aspecto importante del tratamiento de mujeres con BA es la identificación de los fracasos medicamentosos y las reinfecciones, porque estas pacientes están expuestas a riesgos de sufrir pielonefritis, salvo que se elimine su bacteriuria por un nuevo tratamiento. Sobre estas bases hay que hacer una o dos semanas después del tratamiento, cultivo de orina y a partir de esa fecha, repetirlos cada mes por el resto del embarazo. Al hacer los cultivos de orina en intervalos apropiados después del tratamiento, el médico puede identificar la infección recurrente del riñón o la vejiga al detectar el tipo de recurrencia, ésto es, reinfección o recaída se defina como la infección ocasionada por la misma especie y cepa, con tipo específico de microorganismo que estaba antes del tratamiento lo cual representa un fracaso terapéutico. Todas las recaídas aparecen en término de dos semanas (por lo regular en un lapso menor de 5 días) de terminado el tratamiento y se acompaña de infección renal y no vesical. La recurrencia o recaídas mencionadas deben tratarse nuevamente con base en los datos del antibiograma con agentes microbianos a altas dosis durante dos o tres semanas por lo menos.

La reinfección es la infección recurrente por una especie diferente de bacterias después del tratamiento satisfactorio inicial. Dichas infecciones suelen limitarse a la vejiga y no aparecen hasta tres o más semanas después del tratamiento. La reinfección identifica a las mujeres que, a pesar del buen tratamiento inicial están expuestas a mayor riesgo de episodios repetitivos de bacteriuria durante el embarazo razón por la cual son tratadas mejor con otro lapso breve de antimicrobianos, seguidos de tratamiento profiláctico a largo plazo con baja dosis, durante el resto del embarazo. La nitrofurantoina (100 mg cada noche) o la ampicilina (250 mg) cada noche, suelen ser eficaces como agentes supresores de infecciones urinarias crónicas (14).

\section{MATERIAL Y METODOS}

Desde hace mucho tiempo se reconoce la frecuencia y. seriedad de las infecciones urinarias asintomáticas del embarazo.

Desde mediados de 1985, los resultados de los estudios demuestran que:

1. La Bacteriuria Asintomática es un hallazgo relativamente común en la mujer embarazada. 
2. Del 30 al $40 \%$ de las grávidas con Bacteriuria Asintomática desarrollan pielonefritis aguda si no se tratan adecuadamente.

3. Las infecciones urinarias sintomáticas aumentan el riesgo de prematurez.

4. Los episodios de pielonefritis aguda son ampliamente prevenibles y puede reducirse la tasa de prematurez por medio de un tratamiento temprano y adecuado de la Bacteriuria Asintomática.

De acuerdo con estas premisas, se propuso en el Departamento de Ginecología y Obstetricia de la Facultad de Medicina de la Universidad Nacional un estudio de tipo prospectivo y descriptivo, donde se evaluó la epidemiología, diagnóstico, manejo y pronóstico de la Bacteriuria Asintomática en la gestación, con pacientes que asistieron a control prenatal en el Instituto Materno Infantil de Bogotá y Clínica Hospital Fray Bartolomé de las Casas desde el 1o. de mayo de 1987 hasta el 30 de abril de 1988.

Los objetivos específicos fueron:

1. Identificación de las pacientes embarazadas con Bacteriuria Asintomática.

2. Frecuencia e incidencia de las pacientes embarazadas con Bacteriuria Asintomática.

3. Conocer los factores predisponentes y concomitantes en las pacientes con Bacteriuria Asintomática.

4. Identificar los gérmenes más frecuentes relacionados con la Bacteriuria Asintomática.

5. Valorar la eficacia del tratamiento de la Bacteriuria Asintomática.

6. Practicar seguimiento adecuado para descubrir la persistencia y recidiva de la Bacteriuria Asintomática.

7. Análisis de la morbilidad perinatal de las pacientes con Bacteriuria Asintomática.

La muestra se manejó de la siguiente manera:

1. A todas las pacientes en su primera visita de control prenatal se les solicitó Urocultivo, antibiograma y recuento de colonias.
2. A las pacientes con Bacteriuria Asintomática se les llenó la Historia Clínica, según el formulario precodificado.

3. A las pacientes con Bacteriuria Asintomática se les trató con un antibiótico por diez días de acuerdo con el antibiograma.

4. A las 72 horas de iniciado el tratamiento y a los 5 días de terminado se hizo urocultivo y luego cada mes hasta el término del embarazo y sexta semana del puerperio.

5. Las pacientes que presentaron recidivas o reinfección se trataron de acuerdo con el antibiograma.

6. Se valoró el peso del recién nacido, capurro y la morbilidad neonatal temprana.

Los resultados se presentaron con base en 28 pacientes que ya estaban desembarazadas en el momento de terminado el estudio.

\section{RESULTADOS}

\section{Frecuencia de la Bacteriuria Asintomática}

1.238 pacientes asistieron a control prenatal entre el 1o. de mayo de 1987 y el 30 de abril de 1988, a quienes se les practicó urocultivo, de las cuales 37 presentaron urocultivo positivo con más de 100.000 colonias por cc. para una frecuencia del $3 \%$. Fig. 1.

FIGURA 1

FRECUENCIA
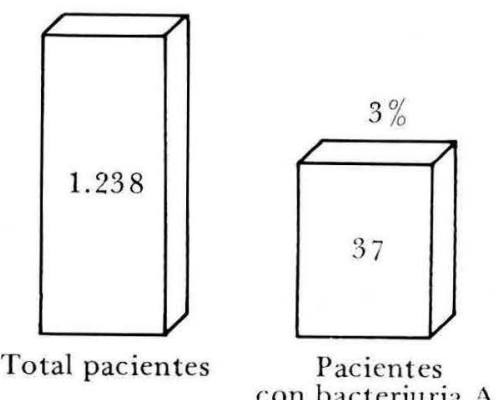

\section{Identificación de la paciente con} Bacteriuria Asintomática

\section{A. Edad}

La edad de nuestras pacientes varió entre los 16 y 42 años. $22(80 \%)$ cstaban entre los 20 y los 35 años. Fig. 2. 
FIGURA 2

EDAD

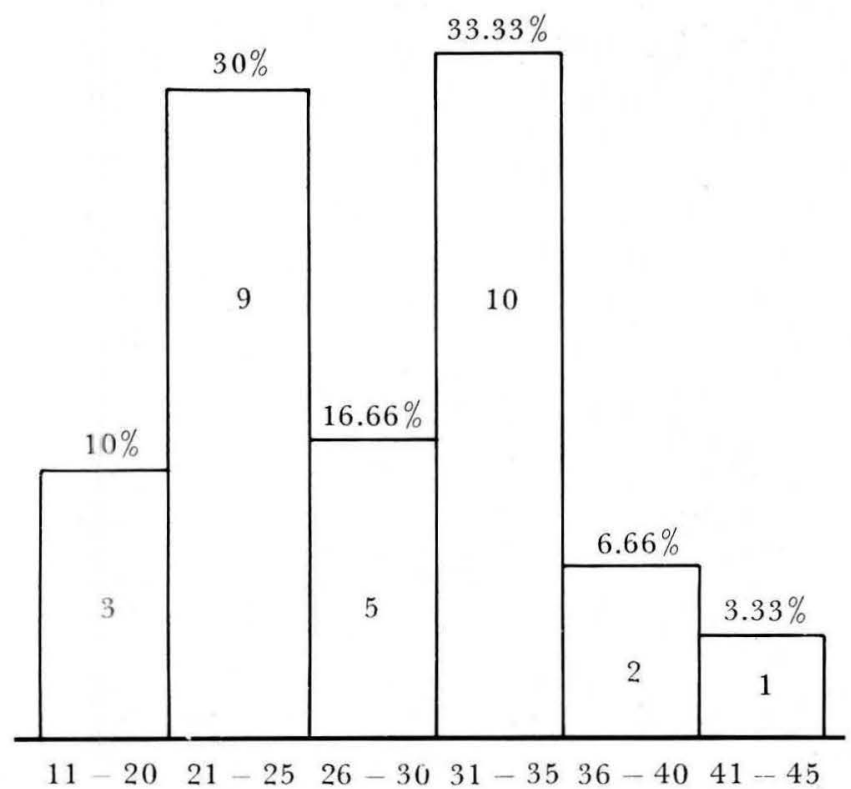

\section{B. Paridad}

Hubo $12(40 \%)$ de primíparas y $18(60 \%)$ de multíparas. Hubo un caso de gran multípara. Fig. 3.

\section{FIGURA 3}

PARIDAD

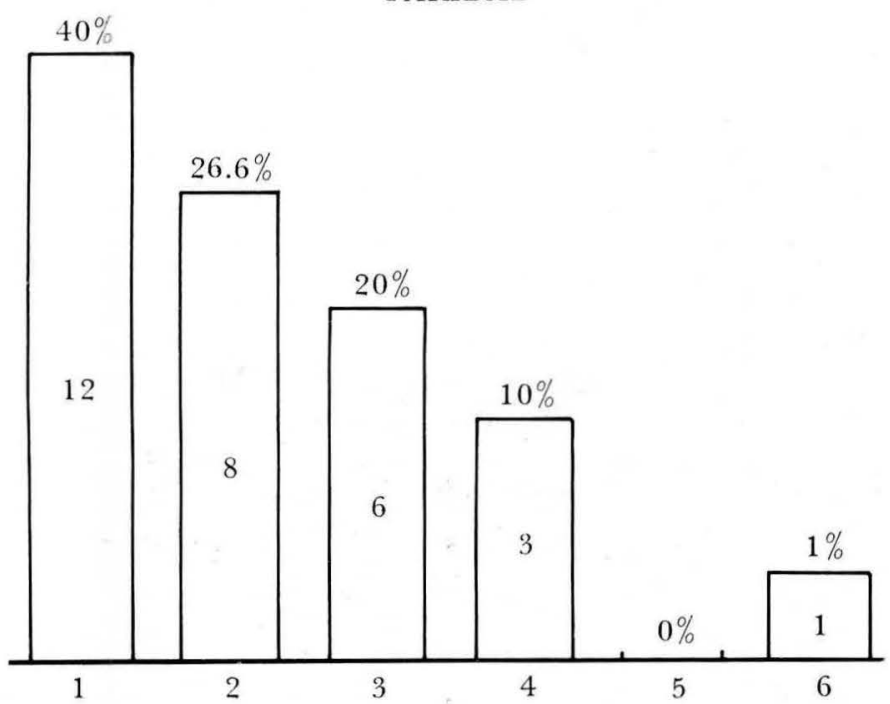

C. Raza

$11(36.6 \%)$ fueron de raza blanca y $19(63.3 \%)$ de raza mestiza. Fig. 4.
FIGURA 4

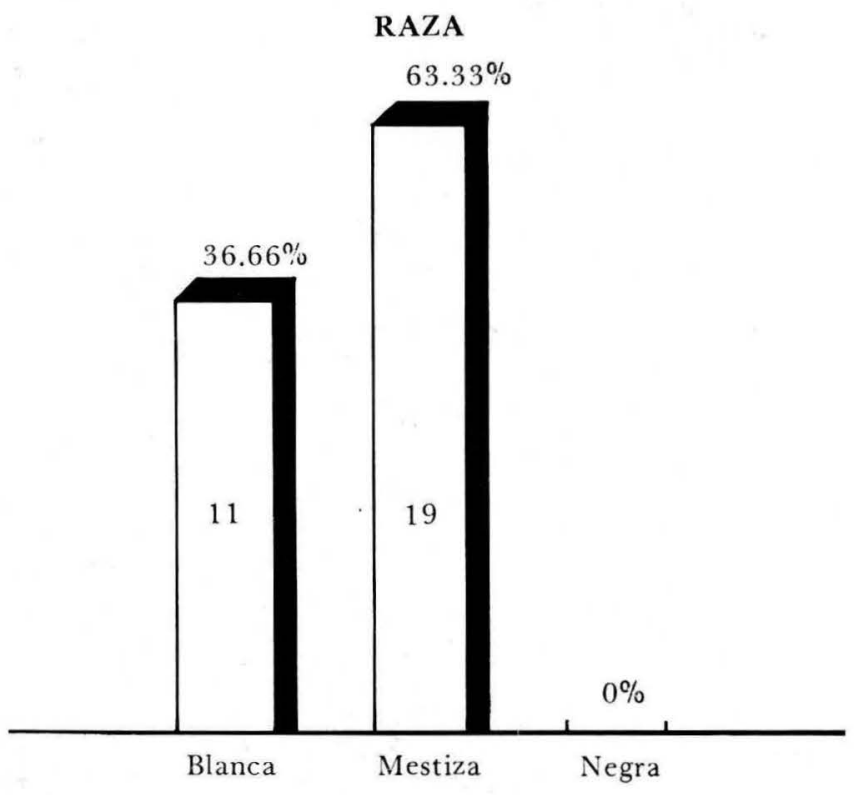

D. Nivel socioeconómico

$14(46.6 \%)$ fueron de nivel socioeconómico bajo, $15(50 \%)$ medio y $1(3.3 \%)$ alto. Fig. 5 .

FIGURA 5

NIVEL SOCIOECONOMICO

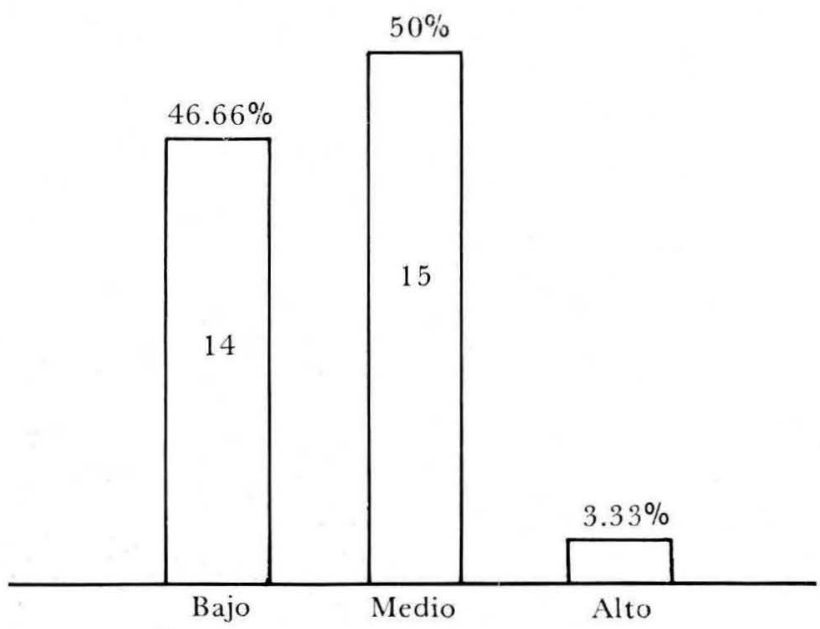

Factores predisponentes y concomitantes

\section{A. Antecedentes médicos personales}

$2(6.66 \%)$ pacientes tenían el antecedente de haber sufrido eclampsia-preeclampsia en anteriores partos; una $(3.3 \%)$ tenía antecedente de enfermedad renal crónica y una $(3.3 \%)$ tenía antecedente de anemia moderada severa. Fig. 6. 
FIGURA 6

\section{ANTECEDENTES PERSONALES}

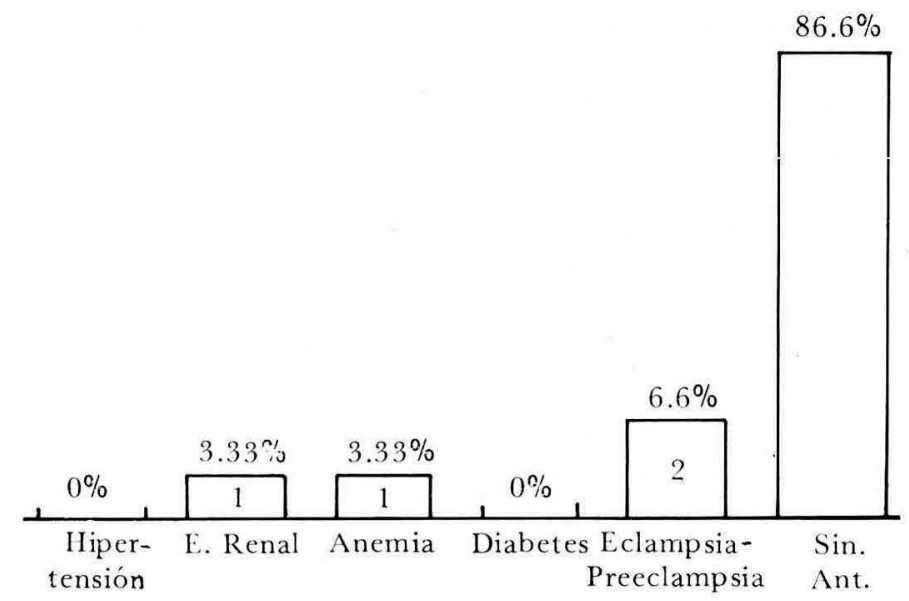

\section{B. Factores concomitantes}

1. HEMOGLOBINA: $1(3.33 \%)$ tenía Hb menos de $10 ; 14(46.66 \%)$ entre 10 y 12 , y $15(49.99)$ entre 13 y 16 . Fig. 7 .

\section{FIGURA 7}

HEMOGLOBINA

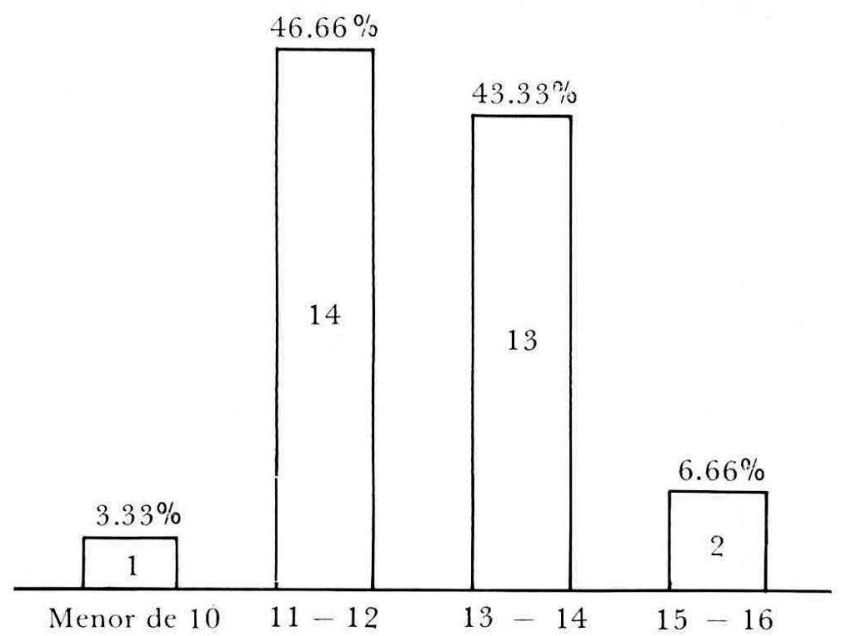

2. GLICEMIA: Se practicó glicemia pre y post a las 2 horas y fue normal en todas las pacientes. Fig. 8.

3. FROTIS VAGINAL: $9(30 \%)$ de las pacientes presentaban flujo genital durante su primer control prenatal de las cuales 5 reportaron monilias y 4 inespecífico.

4. PARCIAL DE ORINA: En las pacientes con Bacteriuria Asirtomática $18(60 \%)$ tenían ni- tritos positivos y $21(70 \%)$ tenían bacterias 3 ó 4 cruces. Fig. 9 y 10.

FIGURA 8

GLICEMIA

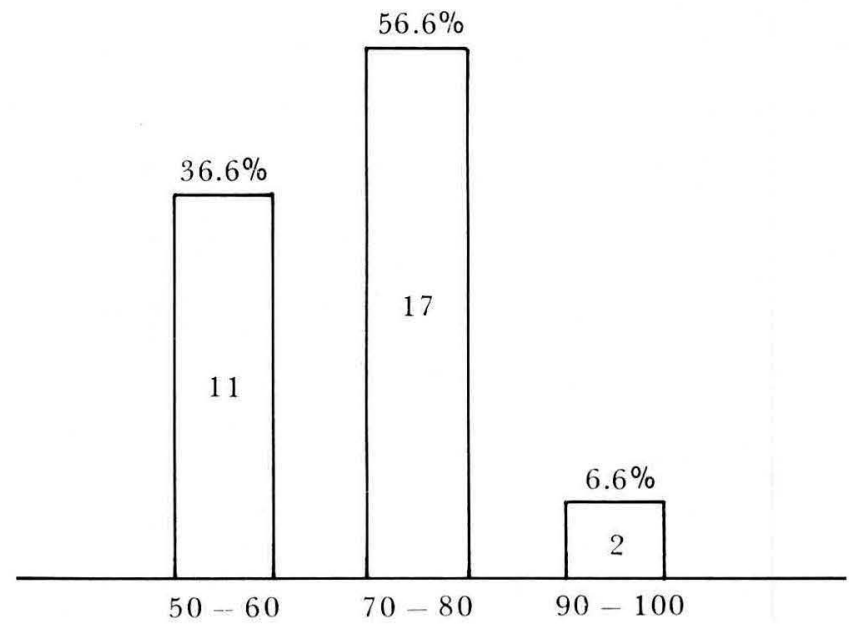

FIGURA 9

PRESENCIA DE NITRITOS EN EL PARGIAL DE ORINA

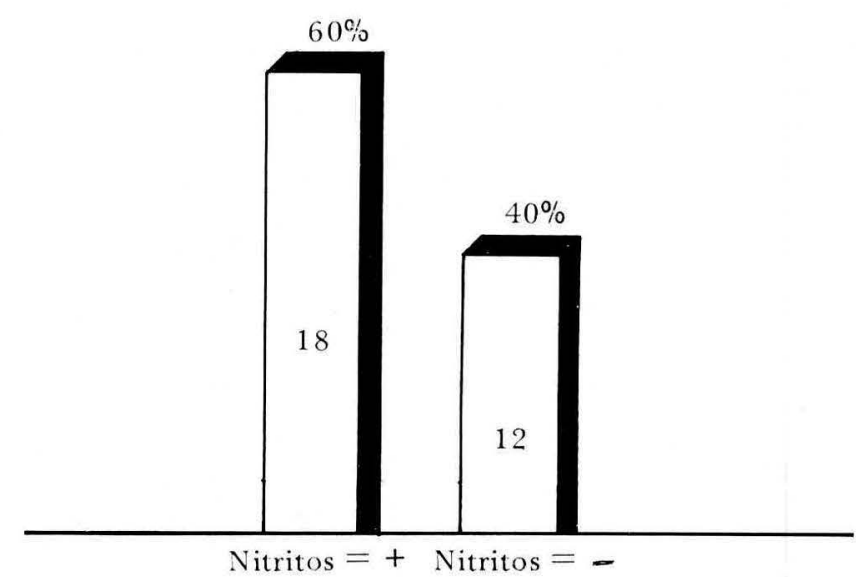

FIGURA 10

PRESENCIA DE BACTERIAS

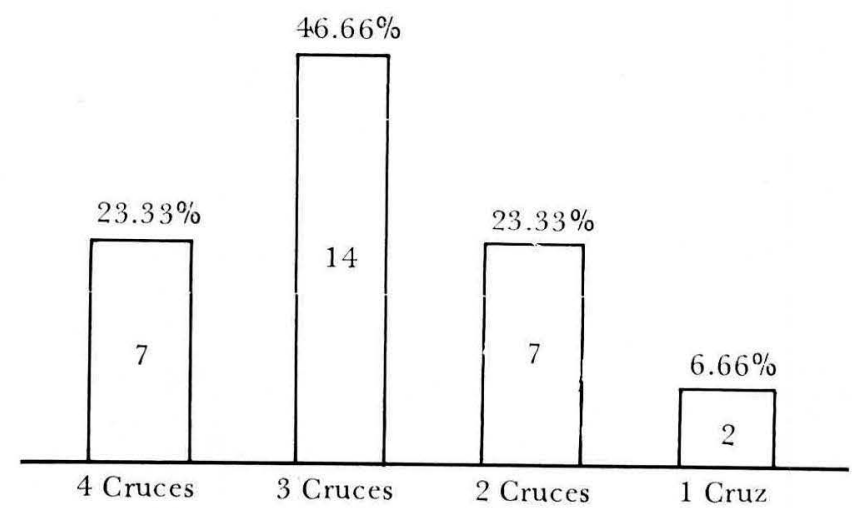


Edad gestacional al tiempo del diagnóstico

El diagnóstico de Bacteriuria Asintomática se realizó en $7(23.3 \%)$ en el primer trimestre; en 12 $(40 \%)$ en el segundo trimestre y en 11 en el tercer trimestre. Fig. 11.

FIGURA 11

\section{DIAGNOSTICO X EDAD GESTACIONAL}

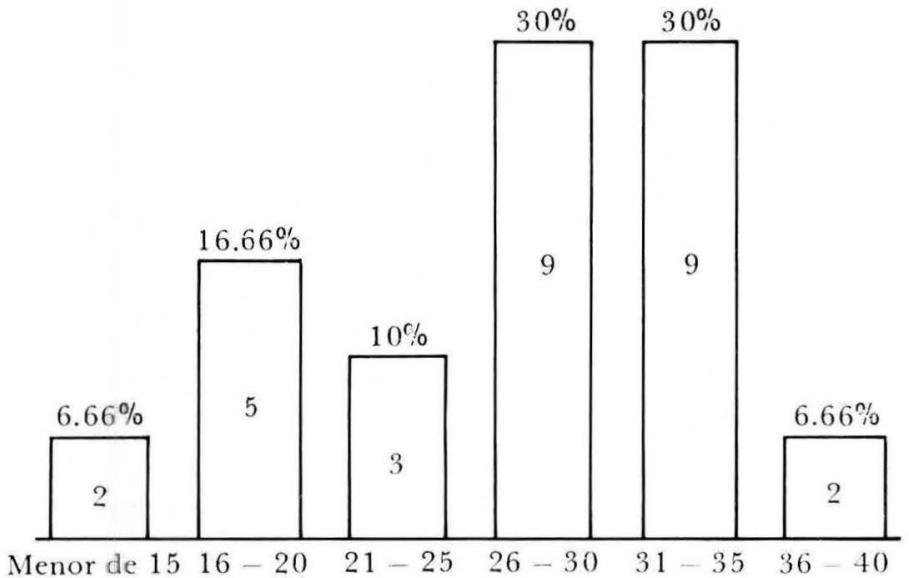

Identificación de los microorganismos

Ll germen más frecuentemente encontrado en las pacientes con Bacteriuria Asintomática fue el E. Coli en 22 (73.3\%); Klebsiella en 2 (6.6\%); Estafilococo Aureus coagulasa positivo en 2 (6.6\%); Enterobacter en $2(6.6 \%)$; Proteus en $1(3.33 \%)$ y Morganela en 1 (3.33\%), Fig. 12 .

\section{FIGURA 12}

IDENTIFICACION DE MICROORGANISMOS

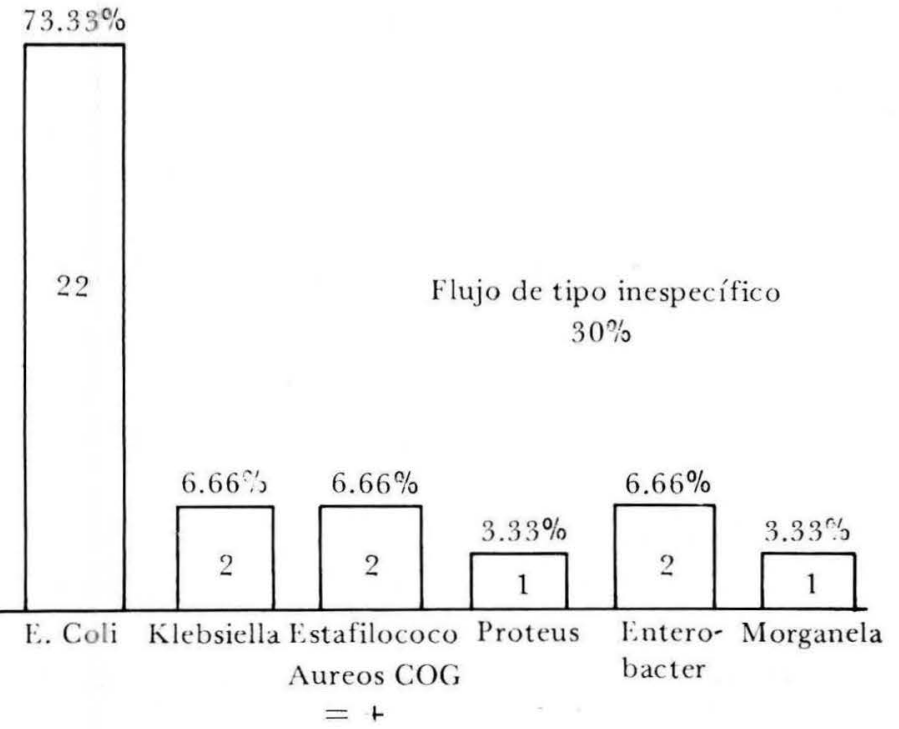

Sensibilidad de los microorganismos al antibiograma

Los microorganismos encontrados en la Bacteriuria Asintomática presentaron la siguiente sensibilidad a los antimicrobianos: A Ampicilina $50 \%$, a Trimetropin sulfa $10 \%$, a Gentamicina $50 \%$, a Cefalosporina $50 \%$, a Acido Nalidixico $50 \%$ y a Nitrofurantoina macrocristales $87 \%$. Fig. 13 .

FIGURA 13

\section{SENSIBILIDAD DE LOS GERMENES A LOS ANTIBIOTICOS}

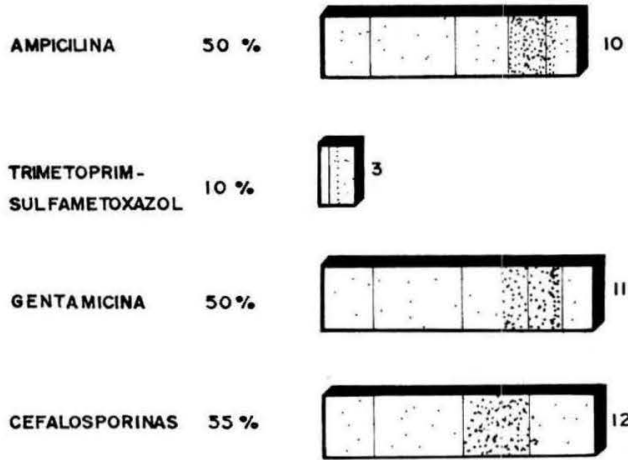

ACIDO NALIDIXICO $50 \%$
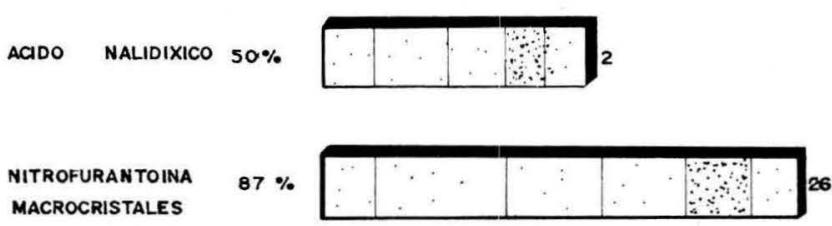

Tratamiento de la Bacteriuria Asintomática

El tratamiento se realizó de acuerdo con el antibiograma: $26(87 \%)$, recibieron nitrofurantoina macrocristales $100 \mathrm{mg}$ cuatro veces al día por 10 días; 2 (7\%) recibieron eritromicina $500 \mathrm{mg}$.cuatro veces al día por 10 días; 1 (3\%) recibió ampicilina 1 g. cuatro veces al día por 10 días y 1 (3\%) amoxicilina $1 \mathrm{~g}$. cuatro veces al día por 10 días. Fig. 14.

FIGURA 14

\section{TRATAMIENTO}

NITROFURANTOINA MACROCRISTALES
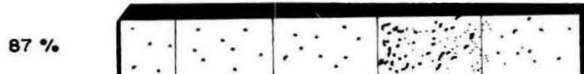

ERITROMICINA

$7 \%$

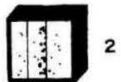

AMPICILINA

$3, \%$<smiles>C1=C[I-]C=C1</smiles>

AMOXILINA

$3 \%$ 


\section{Urocultivo a las 72 horas de iniciado el tratamiento}

A $24(80 \%)$ se les practicó urocultivo a las 72 horas y fueron negativos. Una paciente tenía nitritos positivos a las 72 horas. Fig. 15.

FIGURA 15

\section{PERSISTENCIA}

UROCULTIVO A LAS 72 HORAS

$80 \%$ PACIENTES

$\begin{array}{lrc}\text { Negativo } & 24 & 100 \% \\ \text { Positivo } & 1 & *\end{array}$

Urocultivo a los 5 días de terminado el tratamiento

A $24(80 \%)$ pacientes se les practicó urocultivo a los 5 días de terminado el tratamiento de los cuales $1(4.1 \%)$ fue positivo, recibiendo nuevamente tratamiento de acuerdo con el antibiograma. Fig. 16.

FIGURA 16

\section{RECIDIVA}

UROCULTIVO

A LOS 5 DIAS DE TERMINAR EL TRATAMIENTO

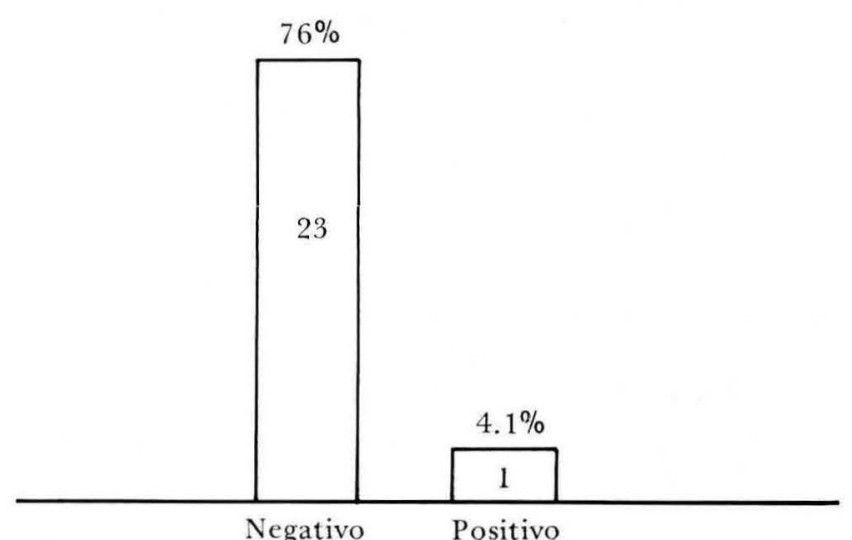

Urocultivo a las 6 semanas del puerperio

A $23(76.6 \%)$ se les practicó urocultivo a las 6 semanas del puerperio los cuales todos fueron negativos. Fig. 17.

\section{Morbilidad materna}

Después de hecho el diagnóstico de Bacteriuria Asintomática durante el control prenatal, 2
$(6.66 \%)$ pacientes presentaron preeclampsia; 4 $(13.3 \%)$ amenaza de parto pretérmino y $2(6.6 \%)$ Ruptura Prematura de Membranas. Fig. 18.

FIGURA 17

UROCULTIVO A LAS 6 SEMANAS DEL PUERPERIO

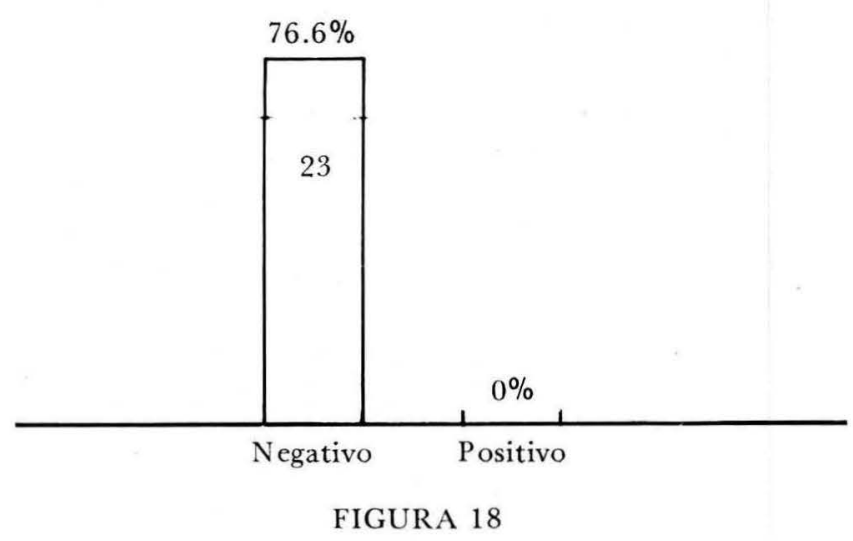

MORBILIDAD MATERNA

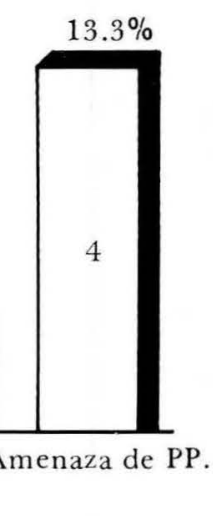

. Morbilidad Perinatal - Resultado Perinatal

PARTO: $22(73.33 \%)$ presentaron parto espontáneo y a $8(26.66 \%)$ se les practicó cesárea por causa obstétrica. Fig. 19, 20.

FIGURA 19

PARTO

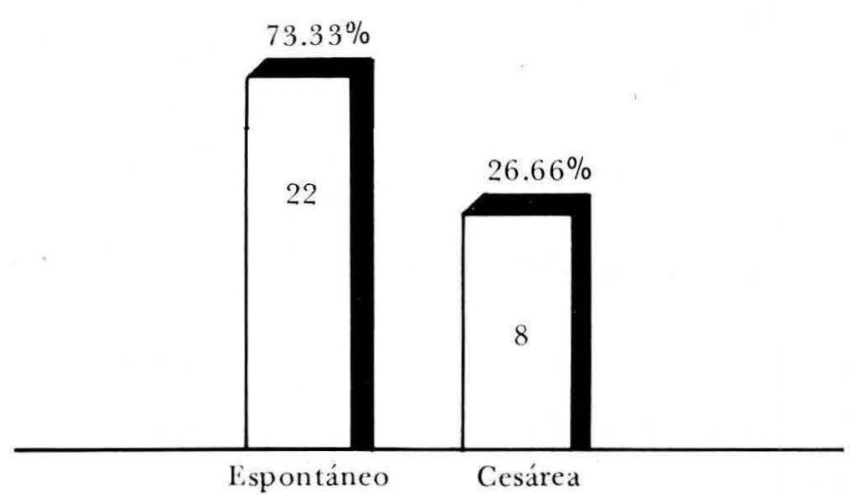


FIGURA 20

\section{CAUSAS DE CESAREAS}

$26.6 \%$

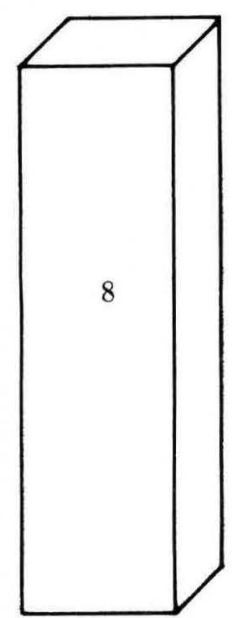

Añosidad: 1

Iterativas: 3

Macrosomia: 2

Sist. Transver.: 1

T. Parto prolongado: 1

SEXO: $21(70 \%)$ fueron de sexo masculino y $9(30 \%)$ femenino.

PESO: $6(20 \%)$ menos de 2.500 gramos, 21 $(70 \%)$ entre 2.500 y 3.999 grs. y $3(10 \%)$ de macrosómicos. Fig. 21.

FIGURA 21

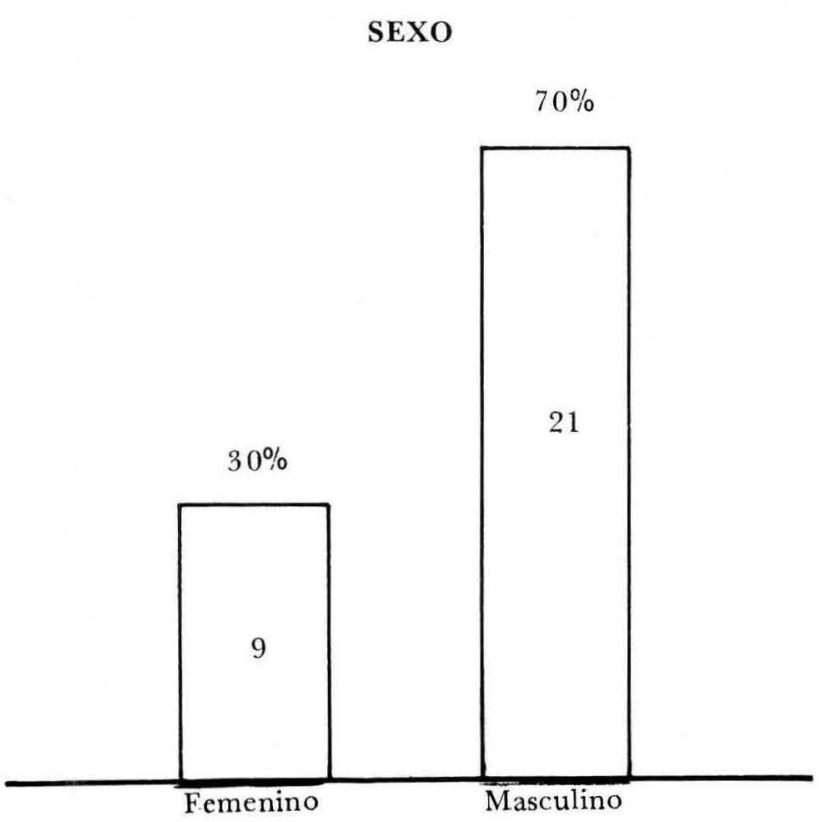

\section{Morbilidad Perinatal - Morbimortalidad Perinatal}

Hubo $4(13.33 \%)$ de recién nacidos pretérmino, $3(10 \%)$ con retardo de crecimiento intrauteri- no y $1(3.3 \%)$ óbito fetal, el cual se presentó en una paciente con preeclampsia IIB sin control prenatal completo. Figs. 22 y 23.

FIGURA 22

\section{PESO DEL RECIEN NACIDO}

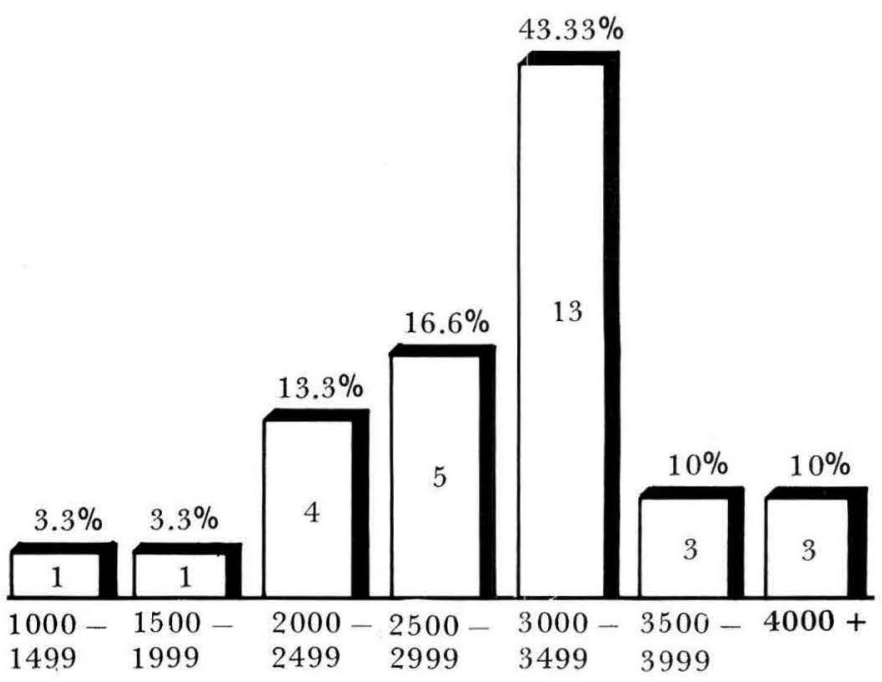

FIGURA 29

MORBILIDAD PERINATAL

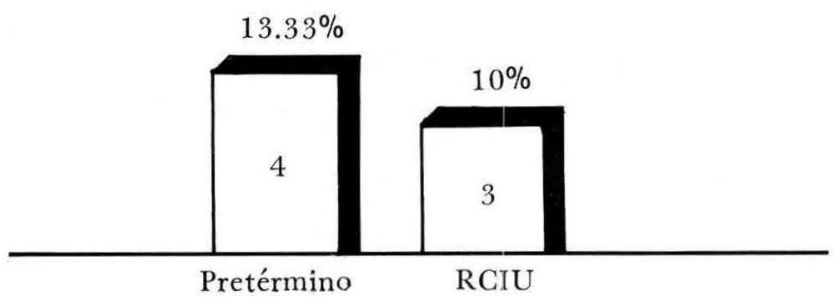

1. La frecuencia de la Bacteriuria Asintomática en la mujer embarazada en control prenatal en el Instituto Materno Infantil y Clínica Hospital Fray Bartolomé de las Casas entre el 1o. de mayo de 1987 y el 30 de abril de 1988 fue del $3 \%$.

2. E1 $80 \%$ de las pacientes con Bacteriuria Asintomática estaban entre los 20 y 35 años; el $60 \%$ eran multíparas. La totalidad del grupo era de raza blanca y mestiza. El $97 \%$ era de nivel socioeconómico medio y bajo.

3. El 33\% tenían factores de riesgo como anemia, preeclampsia, enfermedad renal crónica y flujo genital.

4. No hubo diabéticas en el grupo de estudio. 
5. Al $64 \%$ de las pacientes se les hizo el diagnóstico de Bacteriuria Asintomática en el primero y segundo trimestre.

6. La evaluación de los nitritos positivos y el recuento de leucocitos en el parcial de orina, tienen un valor preditivo de Bacteriuria Asintomática del 60 y $70 \%$ respectivamente.

7. El microorganismo más frecuente fue el E. Coli $(73.3 \%)$.

8. El tratamiento se realizó de acuerdo con el antibiograma teniendo en cuenta las drogas que se pueden utilizar durante el embarazo.

9. La persistencia de la Bacteriuria Asintomática fue del $4 \%$. La recidiva después del tratamiento fue el $4.1 \%$ y no se presentó Bacteriuria a la sexta semana del puerperio por lo cual no se hicieron exámenes complementarios de función renal.

10. La morbilidad materna fue del 26\%(amenaza de parto pretérmino, preeclampsia y RPM).

11. No hubo Pielonefritis en las pacientes tratadas con Bacteriuria Asintomática en nuestro estudio.

12. La morbilidad perinatal fue del $23 \%$ (Pretérmino y Retardo de crecimiento intrauterino).

13. La muerte perinatal se presentó en una paciente con preeclampsia II B que no continuó su control prenatal y presentó óbito fetal a las 30 semanas de gestación con un peso aproximado de 900 grs.

\section{RESUMEN}

Se analiza la epidemiología, diagnóstico, manejo y pronóstico de la Bacteriuria Asintomática en las pacientes que asistieron a control prenatal en el Instituto Materno Infantil de Bogotá y Clínica Hospital Fray Bartolomé de las Casas, desde el 1o. de mayo de 1987 hasta el 30 de abril de 1988.

La frecuencia de la Bacteriuria Asintomática en la mujer embarazada fue del 3\% . E1 $80 \%$ de las pacientes estaban entre los 20 y 35 años. El 60\% eran multíparas; la totalidad de raza blanca y mestiza y el $97 \%$ de nivel socioeconómico bajo y medio.

E1 33\% tenían factores de riesgo como anemia, preeclampsia, enfermedad renal crónica y flujo genital.

En el $64 \%$ se hizo el diagnóstico en el primero y segundo trimestre, siendo el E. Coli el germen más frecuente $(73 \%)$ y el tratamiento se hizo de acuerdo con el antibiograma, teniendo en cuenta las drogas que se pueden utilizar durante el ambarazo, con una persistencia del $4 \%$ y una recidiva del $4.1 \%$ y ninguna paciente presentó pielonefritis.

La morbilidad materna fue del 26\%: Amenaza del parto pretérmino, preeclampsia y RPM. La morbilidad perinatal fue del 23\%: Pretérmino y Retardo del crecimiento intrauterino.

\section{BIBLIOGRAFIA}

1. WHALLEY, PJ.; CUNNINGHAM, F.G.; MARTIN, F.G. Transient renal Dysfunction associated with acute pyelonephritis of pregnancy. Obstet. Gynecol. 46: 174, 1975.

2. GILSTRAP, L.C. III; CUNNINGHAM, F.G.; WHALLEY, P.J. Acute Pyelonephritis in Pregnancy: a retrospective Study. Obstet. Gynecol, 57: 409, 1981.

3. WHALLEY, P.J. Bacteriuria of pregnancy. Am. J. Obstet. Gynecol, 97: 723, 1967.

4. BRUMFITT, W. Los efectos de la Bacteriuria en el embarazo sobre la salud materna y fetal. Kidney International, 8: 113, 1975.

5. HILL, J.A. Frequency of asymtomatic bacteriuria in Preeclampsia. Obstet. Gynecol, 67: 4: 529, 1986.

6. Whalley, P.J.; MARTIN, F.G.; PRITCHARD, J.A. Sickle cell trait and urinary tract infeccion during pregnancy. JAMA 189: 903, 1964.

7. HARRIS, R. Infección aguda del tracto urinario y problemas posteriores. Clínicas Obstétricas y Ginecológicas, 4: 1109, 1984 .
8. HANKINS, G.D.; WHALLEY, P.J. Infecciones agudas de vías urinarias durante el embarazo. Clínicas Obstétricas y Ginecológicas, 2: 3309, 1985.

9. RONALD, A.R. Conceptos actuales en el tratamiento de infecciones de vías urinarias en adultos.

10. KRIEGER, J.N. Complicaciones y tratamiento de las infecciones del tracto urinario durante el embarazo. Clin. Urol. of North Am. 13, 4: 685, 1986.

11. SAVAGE, W.E.; SAMIR, N.H.; KASS, E. Demographic and Prognostic Characteristics of Bacteriuria in Pregnancy. Printed in USA. 4, 5: 385, 1967.

12. WHALlEY, P.J. Bacteriuria of Pregnancy. Am. J. Obst. Gin. 97: 723, 1967.

13. WHALLEY, P.J. Short Term Versus Continuos antimicrobial therapy for asymptomatic bacteriuria in pregnancy. Obstet and Gynecol. 49: 262, 1977.

14. KENNETH, J.L. and Cols. Bladder versus renal bacteriuria during pregnancy: Recurrence after treatment. Am. J. Obstet Gynecol. 139, 4: 404, 1981. 